\title{
LA OMISIÓN DEL DOLO POR PARTE DEL LEGISLADOR EN EL SUPUESTO DE HECHO DEL ARTÍCULO $1233^{\circ}$ DEL CÓDIGO CIVIL
}

\author{
THE OMISSION OF THE DOLL BY \\ THE LEGISLATOR IN THE ASSUME OF \\ THE FACT OF ARTICLE $1233^{\circ}$ OF THE CIVIL CODE
}

Piero Augusto Da Giau Roose*

\footnotetext{
Maestro en Derecho Civil y Comercial por la Universidad de San Martín de Porres. Abogado por la misma casa de estudios. Docente en la UNIFE, Universidad ESAN, Escuela Militar de Chorrillos "Francisco Bolognesi", Academia de la Magistratura, Universidad Nacional "José Faustino Sánchez Carrión", Escuela Nacional de Control. Expositor en temas de Derecho Cambiario en el llustre Colegio de Abogados de Lima. Autor de diversos libros de la Especialidad.
}

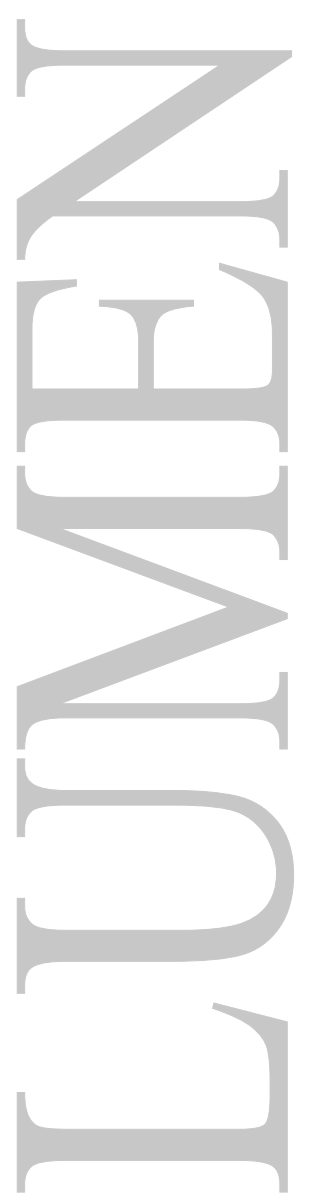




\title{
LA OMISIÓN DEL DOLO POR PARTE DEL LEGISLADOR EN EL SUPUESTO DE HECHO DEL ARTÍCULO $1233^{\circ}$ DEL CÓDIGO CIVIL
}

\author{
THE OMISSION OF THE DOLL BY THE LEGISLATOR IN THE ASSUME OF THE FACT OF \\ ARTICLE $1233^{\circ}$ OF THE CIVIL CODE
}

Piero Augusto Da Giau Roose

\begin{abstract}
Resumen:
El artículo $1233^{\circ}$ del Código Civil Peruano de 1984, fue elaborado mientras se encontraba aún vigente la derogada Ley de Títulos Valores $N^{\circ} 16587$, cuerpo normativo que regulaba únicamente cuatro títulos valores: La letra de cambio, el pagaré, el cheque y el vale a la orden. En la actualidad, se han sumado a los tres primeros citados, un gran número de títulos valores que incorporan derechos de diversa naturaleza que pueden encajar en una promesa o una orden de pago, generando la necesidad de analizar con profundidad los alcances de la acotada norma. Adicionalmente, el artículo analizado, influenciado por la legislación extranjera, no ha previsto el actuar doloso del acreedor, limitándose exclusivamente a la culpa y no al dolo. Ello nos permite afirmar la existencia de conductas no reguladas, a las cuales, no se les vincula una consecuencia jurídica determinada. Lo anteriormente descrito genera la necesidad de modificar la norma sustantiva acotada y vincularla con profundidad a la Teoría de las Obligaciones y a la Nueva Ley de Títulos Valores № 27287.
\end{abstract}

\section{Palabras clave:}

Obligaciones, prestaciones, acreedor, deudor, pago, dolo, culpa, supuesto de hecho, títulos valores, protesto, título ejecutivo, perjuicio, obligación primitiva.

\begin{abstract}
:
The article 1233 of the Peruvian Civil Code from 1984 developed while the repealed "Securities Act No. 16587" was still in force and regulating only four securities: The bill of exchange, promissory note, check and voucher to order. At present, have been added to the first three mentioned, a large number of securities that incorporate rights of various kinds that can fit into a promise or a payment order, that generates the need to analyze in depth the scope of the regulation. Additionally, the article analyzed, influenced by foreign law, has not provided the intentional act of the creditor, limited only to blame and not malice. This allows us to affirm the existence of unregulated behaviors with no specific legal consequence. The above described generates the need to modify this regulation and link it deeply to the "Obligations Theory" and in the new "Securities Act No. 27287
\end{abstract}

\section{Key words:}

obligations, benefits, creditor, debtor, payment, malice, blame, assumptions, securities, protest, enforcement order, damage, primitive obligation.

\section{EL DERECHO DE LAS OBLIGACIONES EN SU SENTIDO TERMINOLÓGICO Y SU RAICES "OB LIGATIO" U "OB LIGARE"}

El maestro Josserand señalaba que el Derecho de las Obligaciones es uno de los pilares del Derecho Civil, citado por Alterini, A. (1997:13)

El derecho de las obligaciones no solo constituía el substratum del Derecho, sino de un modo más general, de todas las ciencias sociales "En lo cualitativo-ahora con palabras de 
JOSSERAND- no es exagerado decir que el concepto obligacional constituye el armazón y el substratum del Derecho, y hasta de un modo más general, de todas las ciencias sociales". (El subrayado es nuestro).

Los antecedentes más notables del Derecho de las Obligaciones los hallamos en el Derecho romano, evidenciándose la simplicidad con la que los jurisconsultos de Roma, desarrollaron su dogmática, pasando por etapas que van desde una dureza draconiana que con el transcurso del tiempo fue atenuándose y humanizándose, en tal sentido Borda, G (1980:13) señala:

La ley Poetelia Papiria (326 a.C.) marcó una etapa fundamental de esta evolución; abolió el nexum, o sea, la vinculación corporal del deudor; todavía el acreedor, cuyo crédito no era satisfecho, conservaba la facultad de tomarlo y exigirle sus servicios, hasta que el precio de estos compensara la deuda; pero no podía ya encadenarlo, ni azotarlo, ni venderlo como esclavo. Poco a poco fue sintiéndose lo inadecuado de la objetivación de la obligación en la persona del deudor; en lugar de la responsabilidad de la persona fue apareciendo la del patrimonio.

Para entender a cabalidad el alcance y sentido verdadero de este pilar del Derecho, debemos escudriñar en sus raíces y asimilar paulatinamente el significado de sus instituciones. El término obligación proviene de las raíces latinas "ob" "ligatio" u "ob" "ligare", en términos muy simples podemos concluir en: "a lo que está alrededor de" o "en torno a". Con una finalidad estrictamente didáctica y utilizando la mayéutica, sería válido preguntarnos ¿Alrededor de qué? La respuesta la hallamos en la relación jurídica, ergo, la obligatio es aquello que está alrededor de la relación o vínculo que se da entre dos sujetos - incluyéndolos- estos sujetos son denominados acreedor y deudor o, en todo caso, sujeto activo y sujeto pasivo, respectivamente.

La sencillez con la que describimos la obligatio es la misma con la que Roma desarrollo este pilar o columna sostén del Derecho civil. Los elementos objetivos de la obligatio son por una parte la relación jurídica y por otra la prestación, entendida esta última como conducta consistente en un dar, un hacer o un no hacer. Sectores de la doctrina han incluido adicionalmente la conducta consistente en el garantizar, tal como ocurre en el caso del avalista o el fiador. Véase Código Civil Italiano "Art. 1179 Obbligo di garanzia.- Chi è tenuto a dare una garanzia, senza che ne siano determinati il modo e la forma, può prestare a sua scelta un'idonea garanzia reale o personale, ovvero altra sufficiente cautela". (Obligación de Garantizar quién está obligado a dar una garantía, sin que se hayan determinado el modo y forma, puede prestar a su elección garantía adecuada o personal, o cualquier otra suficiente cautela).

En tiempos remotos no existía el Derecho y se imponía la ley del más fuerte. El hombre de las cavernas se apropiaba de los alimentos de otro imponiendo su fuerza bruta. El más débil, en caso de no oponer resistencia, simplemente se sometía a los requerimientos del más fuerte. En ese sentido, el dar no implicaba prestación por muchas razones. En primer lugar, no existe relación jurídica, no hay por tanto obligatio, para que surja la obligación debe aparecer la figura de una autoridad superior que traiga consigo la coercibilidad y posterior coacción en caso de incumplimiento. En el caso de las obligaciones civiles o perfectas, el acreedor tiene la facultad de recurrir a la fuerza pública en caso de incumplimiento.

Con el pasar del tiempo y la evolución del hombre, aparece la sociedad y es de aplicación la máxima "ubi societas, ibi ius": donde hay sociedad, hay derecho. Se pasa de la banda a la figura de la tribu, entendida como un conjunto de familias unidas por la existencia de un antepasado o ancestro común: el tótem. El término tribu es utilizado cotidianamente por los abogados casi sin percatarnos de ello. Por ejemplo, distribuir, tributos, o cláusula de sometimiento a leyes y tribunales. El primer término distribuir está referido a repartir bienes entre la tribu; el segundo término está 
vinculado al aporte de bienes económicos en la tribu y el tercer término se vincula a una elemental y rudimentaria forma de impartir justicia. Roma nace a partir de 4 tribus urbanas y diez tribus rurales.

La obligatio debe ser entendida como una figura propia de la evolución del hombre, la obligatio debe ser analizada también desde la óptica antropológica. Las obligaciones civiles o perfectas son aquellas que facultan al acreedor para acudir a la fuerza pública en caso de incumplimiento. Se dan los elementos de coercibilidad, entendida como la amenaza o aviso de utilización de fuerza, y la coacción, aplicación concreta de la fuerza. Cuando surge la tribu, se evoluciona hacia la heterocomposición y por tanto, la posibilidad teórica de los antecedentes de la obligatio.

La prestación se halla contenida en la obligatio y es uno de sus elementos objetivos. La prestación debe ser entendida de manera sencilla: es una conducta. Pero tal conducta no es cualquier conducta, sino la conducta debida, la conducta previamente acordada, la cual puede consistir en una acción u omisión, cuando se trata de la primera será tanto el dar como el hacer, si se trata del dar podrá, a su vez, referirse al dar una suma de dinero, dar un bien cierto o dar un bien incierto, asimismo también existirá acción cuando se trate de un hacer; en contraposición se podrá entender que una conducta puede radicar en una omisión, entendida como un no hacer, la conducta omisiva puede significar conducta debida.

La relación jurídica obligatoria puede extinguirse por diversas formas como el pago, la dación en pago, la novación, la compensación, la consolidación o confusión, el muto disenso, la condonación, entre otras. De todas las formas extintivas anteriormente señaladas, es el pago la forma más común $y$, en ese sentido, existe en la doctrina diferentes acepciones de pago. La posición restrictiva de pago, seguida por la escuela alemana, afirma que únicamente se puede hablar de pago en las obligaciones con prestación de dar suma de dinero, mientras que otras posiciones refieren que el pago podría configurarse únicamente en caso de acción mas no de omisión, vale decir en las obligaciones con prestación de de dar suma de dinero y en las obligaciones con prestación de hacer, excluyendo a las prestaciones de no hacer. La posición extensiva de pago abarca todas las clases de prestaciones y, es más, se llega al extremo de referir al pago como cualquier forma de extinción de las obligaciones, basta que genere solutio. La acepción correcta de pago es la que lo describe como la forma más común de extinción de las obligaciones, posición mayoritaria, por tanto, no toda forma de extinción de las obligaciones será entendida como pago.

Desarrollando el tema antes descrito encontramos lo señalado por el maestro Alterini, A(1997:91)

El sustantivo pago tiene diversas acepciones: Vulgarmente se entiende por pago el cumplimiento de las obligaciones de dar suma de dinero; esta misma es la acepción del Código Civil alemán. En sentido amplísimo, según fórmula de Paulo en el Digesto, se entendió por pago cualquier forma de solutio, esto es, de extinción de la obligación aunque el acreedor no se satisficiera específicamente.

La voz pago proviene del latín pacare o pagare que simplemente significa desatar, desunir, desvincular. Si la obligatio gira en torno a un vínculo, relación o atadura, pues encontramos que mediante el pacare o pagare logramos tal desvinculación, sin perjuicio de ello, existen otras formas menos comunes de extinción de la obligatio. El Código civil vigente no se define qué es el pago, sin embargo se señala en el artículo $1220^{\circ}$ "Se entiende efectuado el pago sólo cuando se ha ejecutado integramente la prestación".

En términos muy sencillos entenderemos como pago la ejecución íntegra de la prestación y, por tanto, si la prestación es entendida como conducta, podemos inferir que el pago corresponderá a la conducta debida previamente pactada, ejecutada en su integridad, la cual puede consistir en una conducta de dar, conducta de hacer o conducta omisiva: un no hacer. 


\section{UNA APROXIMACIÓN EXEGÉTICA AL ARTÍCULO $1233^{\circ}$ DEL CÓDIGO CIVIL}

El artículo $1233^{\circ}$ del Código civil señala "La entrega de títulos valores que constituyen órdenes o promesas de pago, sólo extinguirá la obligación primitiva cuando hubiesen sido pagados o cuando por culpa del acreedor se hubiesen perjudicado, salvo pacto en contrario. Entre tanto la acción derivada de la obligación primitiva quedará en suspenso".

El articulo previamente citado merece una especial atención pues más allá de su sucinto desarrollo encierra mucha complejidad y requiere de un tratamiento especial pues en él no solo hallamos normas propias del Derecho civil, sino conceptos propios del Derecho cartular, área que muchas veces no es entendida en su real dimensión por los civilistas en sentido estricto, generando dudas en cuanto a la correcta aplicación de los principios y normas eminentemente cartulares, asimilables comúnmente por los especialistas en Derecho cambiario.

El antecedente histórico más inmediato en nuestra legislación es el artículo $1248^{\circ}$ del Código Civil de 1936, el cual señalaba: "La entrega de pagarés a la orden, de letras de cambio u otros documentos, sólo producirá los efectos del pago cuando hubiesen sido realizados, o cuando por culpa del acreedor se hubiesen perjudicado. Entre tanto, la acción derivada de la obligación primitiva quedará en suspenso".

La legislación cambiaria reguló fundamentalmente a la letra de cambio y el pagaré, siendo que la LTV N 16587, vigente desde el 15 de septiembre de 1967, posteriormente reguló el vale a la orden, hoy en desuso. Con anterioridad a la precitada norma, los títulos valores fueron regulados por el Código de Comercio de 1902, hasta que por Ley N 6606 se encomendó la Comisión reformadora del Código de Comercio, el cual regulaba a la letra de cambio en la sección décima y a los vales, pagaré a la orden y cheques en la sección undécima, todos ellos derogados por el artículo $214^{\circ}$ de la LTV N¹6587, anteriormente referida.

Desde la óptica de los Derechos reales, los títulos valores son bienes muebles, razón por la cual, el primer término materia de análisis, es la entrega o tradición que proviene del latín traditio y éste de tradere, "entregar". La traditio es en términos simples la acción de entregar, entendiendo acción como un movimiento corporal que causa una modificación del mundo exterior y generando consecuencias jurídicas. Esta acción de entregar supone transferencia o traspaso, constituye una forma de adquirir la propiedad, específicamente un modo derivativo de adquisición de la misma.

La redacción del artículo $1233^{\circ}$ del Código Civil es el resultado de una notoria influencia del Derecho extranjero, por ejemplo, el Código Civil Español indica en el artículo $1170^{\circ}$ lo siguiente:

El pago de las deudas de dinero deberá hacerse en la especie pactada, y, no siendo posible entregar la especie, en la moneda de plata u oro que tenga curso legal en España. La entrega de pagarés a la orden, o letras de cambio u otros documentos mercantiles, sólo producirá los efectos del pago cuando hubiesen sido realizados, o cuando por culpa del acreedor se hubiesen perjudicado. Entretanto la acción derivada de la obligación primitiva quedará en suspenso.

Al igual que en nuestro país, en el Derecho español se establece que la entrega de títulos valores carecen de eficacia solutoria plena, puesto que únicamente el dinero como medio de pago posee la eficacia solutoria plena y, a la vez, inmediata, por eso doctrinariamente se ha establecido de manera uniforme que la entrega de títulos valores no genera una datio in solutum, ni tampoco existe novación, pues la novación objetiva implica la extinción de un anterior obligación y el nacimiento o surgimiento de una nueva, situación que no se da con la entrega de un título valor pues la relación causal se mantiene viva y subsiste, pero queda en suspenso al haber operado el fenómeno de 
la incorporación cambiaria. El suspenso señalado culmina cuando el título valor se realiza o en términos sencillos: se cobra. En el mismo sentido García-Pita, J (1999:137) señala: “...cuando el título se realiza; es decir: cuando es pagado y cobrado, respectivamente, se producen los efectos solutorios, extinguiéndose ambas obligaciones, la causal y la cartácea".

El tema referido a la emisión del instrumento cambiario y existencia de novación objetiva ha sido desarrollado desde hace mucho tiempo atrás. De este modo, Montoya, U (1982:66) indica:

Se ha debatido en la doctrina sobre si la emisión del documento cambiario produce novación de la obligación fundamental o subyacente, o si esta queda extinguida y surge la cambiaria, que vendría a reemplazarla....pero se advirtió que esta solución resultaba injusta para el acreedor, pues podía ocurrir que quedara privado de toda acción si por cualquier circunstancia, aun cuando fuese involuntariamente, se perjudicaba la acción cambiaria. (El subrayado es nuestro).

En segundo lugar, el artículo bajo análisis restringe el supuesto de hecho, pues no se referiría a todos los títulos valores, sino solo aquellos que constituyen órdenes o promesas de pago. La razón de nuestra afirmación se halla en que el artículo $1233^{\circ}$ del Código Civil fue elaborado tomando como punto de partida a la Ley $\mathrm{N}^{\circ} 16587$, la cual regulaba únicamente cuatro títulos valores: La letra de Cambio, el pagaré, el cheque y el vale a la orden. De los señalados subsisten en la NLTV $\mathrm{N}^{\circ} 27287$, únicamente los tres primeros, precisando que dicho cuerpo normativo entró en vigencia dieciséis años después de la entrada en vigencia del Código Civil, de 1984. Por tanto, se hace necesario un análisis mucho más completo y profundo del artículo en comento, pues el contexto de su dación y elaboración fue distinto al que tenemos el día de hoy.

En tercer lugar, debemos tener en claro que no todos los títulos valores se perjudican, pues no todos los títulos valores se hallan sujetos a protesto. Los títulos valores sujetos al protesto son fundamentalmente los títulos valores a la orden. A continuación, prosiguiendo con el método mayéutico, nos haremos la siguiente pregunta: ¿Todos los títulos valores se protestan? La respuesta será que no, pues los títulos valores sujetos a protesto son fundamentalmente los títulos valores a la orden. Si nos planteamos una segunda pregunta ¿Todos los títulos a la orden están sujetos a protesto? La respuesta será por regla general sí, pero hay excepciones.

Del mismo modo, no será totalmente apropiado nuestro estudio si no definimos con claridad qué es el protesto. Respondiendo a la interrogante afirmaremos que el protesto es una diligencia notarial o judicial que tiene por finalidad dejar constancia de la falta de aceptación o de pago de un título valor. Esta diligencia cumple con dos funciones importantísimas, la primera está referida a la función probatoria que permite acreditar que el título valor no ha sido aceptado o pagado, mientras que la segunda función se denomina la función conservativa. Esta última lo que conserva es la acción, específicamente la acción cambiaria, la cual se clasifica en la acción cambiaria directa, acción cambiaria de regreso y acción cambiaria de ulterior regreso.

El protesto, por lo anteriormente señalado, no solo es una diligencia destinada a la acreditación de un hecho y la conservación de las acciones cambiaria, sino que asimismo plasma el deber de diligencia del tenedor del título valor. Este deber de diligencia ha sido desarrollado por el maestro De Eizaguirre, J (2003:299) "El deber de diligencia, que actúa en contrapartida del mantenimiento en su integridad de los derechos derivados de la letra, consiste en la presentación de la letra al pago dentro de plazo y subsiguiente levantamiento de protesto o sus subrogados legales".

Significa entonces que el tenedor de un título valor a la orden y sujeto al protesto tiene no solamente un derecho a su favor en su calidad de beneficiario, sino que también debe desplegar una conducta diligente destinada a protestar el título valor dentro de los plazos previstos. El no protesto generará el perjuicio del título valor, por tanto no se verificará la función probatoria ni 
la función conservativa del instrumento. Adicionalmente, tal como estamos analizando, será de aplicación en su caso, el artículo $1233^{\circ}$ del Código Civil.

Otra pregunta importante que nos permitirá progresivamente entender a cabalidad el artículo $1233^{\circ}$ del Código Civil es la siguiente ¿Todos los títulos ejecutivos son títulos valores? La respuesta será que no, pues hay muchos títulos ejecutivos que no son títulos valores, por ejemplo, aquellos descritos en el artículo $688^{\circ}$ del Código Civil, dícese las resoluciones judiciales firmes, los laudos arbitrales firmes, las actas de conciliación, el instrumento impago de renta por arrendamiento, entre muchos otros. Continuando con nuestra finalidad didáctica nos haremos otra pregunta ¿Todos los títulos valores serán títulos ejecutivos? Aparentemente la respuesta sería sí, sin embargo, ello no es del todo cierto. Por lo común los títulos valores adquieren mérito ejecutivo y se convierten en títulos ejecutivos, entendiendo estos últimos como documentos o instrumentos en los cuales se han incorporado derechos que se presumen reconocidos pero que no han sido satisfechos, lo cual genera una clase de procesos conocidos doctrinariamente como procesos de ejecución que se contraponen a los procesos de cognición que son aquellos también entendidos como procesos de derecho discutido, puesto que no partimos de presunción de derecho reconocido, sino que el derecho será discutido durante el proceso. En ese sentido la respuesta será que no todo título valor es un título ejecutivo. Doctrinariamente se afirma que la relación entre título ejecutivo y título valor es una relación de género a especie. Para nosotros esa afirmación es errónea, pues no todo título valor es un título ejecutivo o, en todo caso, llega convertirse en él.

El tenedor o beneficiario de un título valor aspira a que éste último se convierta en título ejecutivo. El titulo valor a través de una especie de metamorfosis, logra convertirse en título ejecutivo siguiendo un camino formal y solemne que radica en una diligencia notarial o judicial denominada protesto. Esta diligencia se encuentra regulada y descrita en la NLTV $N^{\circ} 27287$. Del mismo modo, aparecen las denominadas formalidades sustitutorias al protesto que son fundamentalmente las que se derivan de la cláusula de pago con cargo en cuenta o la cláusula de liberación de protesto. Ergo, si un título valor no se protesta dentro de los plazos establecidos por ley, siempre que no se hayan utilizado formalidades sustitutorias, nos encontraremos frente a títulos valores que no lograron convertirse en títulos ejecutivos. Por ello, no todo título valor es un título ejecutivo, al menos afirmaremos que no todo título valor logra convertirse en título ejecutivo, a su vez, lo anteriormente descrito generará que no habrá proceso único de ejecución pues no hay ejecución sin título, nulla executio sine titulo.

El artículo $1233^{\circ}$ del Código Civil señala que la entrega de títulos valores que constituyen órdenes o promesas de pago, sólo extinguen la obligación primitiva cuando hubiesen sido pagados o cuando por culpa del acreedor se hubiesen perjudicado, salvo pacto en contrario. La siguiente pregunta siempre continuando con nuestro estilo didáctico será la siguiente ¿Quién es el más interesado en conseguir que un título valor adquiera mérito ejecutivo? La respuesta es evidente, será al beneficiario o tenedor del mismo y que en la relación causal es por lo común el acreedor, es el beneficiario aquel sujeto cambiario al que le corresponden los derechos incorporados al título. Por ejemplo, en el pagare lo que se incorpora es fundamentalmente el derecho de crédito, recordemos que la deuda corresponde al deudor y el crédito corresponde o beneficia al acreedor. En el caso específico de un pagaré o de una letra de cambio, el más interesado en conseguir que estos títulos valores pasen a convertirse en títulos ejecutivos, es precisamente el beneficiario o tenedor del instrumento.

Volviendo al tema de los mecanismos formales que logran que un título valor a la orden se convierta en un título ejecutivo hemos señalado al protesto o a las formalidades sustitutoria como aquellos mecanismos formales que nos llevan a la metamorfosis título valor - título ejecutivo. Asimismo hemos precisado quién es la persona o sujeto cambiario responsable de impulsar dicha evolución de título valor a título ejecutivo, llegando a la conclusión que corresponde al beneficiario. Es este último al que le debemos exigir diligencia cuando recibe uno o más títulos valores que constituyen órdenes o promesas de pago. 
Volviendo al tema del Derecho de las Obligaciones encontramos que tanto el sujeto activo llamado acreedor como el sujeto pasivo llamado deudor tienen un interés. En el caso del primero es que la prestación se ejecute, ya sea que corresponda a un dar, un hacer o un no hacer. Muchas veces perdemos de vista el interés del deudor. ¿Cuál es la razón por la que el deudor paga o cumple con la prestación a su cargo? Las respuestas podrán ser variadas, algunos dirán porque es lo correcto y ético y por eso cumple y paga; sin embargo, allí no radica la razón o el interés del deudor, pues un deudor paga o ejecuta la prestación para llegar o alcanzar el pagare o pacare y la posterior solutio. Si la obligación es un vínculo que constriñe y faculta al acreedor para acudir a la fuerza pública en caso de incumplimiento, encontramos que el deudor tiene interés en pagar para desvincularse, para destruir el vínculo, para llegar al pagare o pacare que traducido al español significa algo tan simple como desatar y alcanzar la posterior solutio. El deudor cuando paga se libera y recupera su libertad desde el punto de vista obligacional.

Otro tema insoslayable es el efecto del pago pues si lo que se entrega es una suma de dinero el efecto del pago será pro soluto, mientras que la entrega de un título valor dentro de los alcances del artículo $1233^{\circ}$ del Código Civil es pro solvendo, es decir se entiende recibido salvo buen cobro. Durante mucho tiempo ha persistido la discusión doctrinaria referida a la entrega de títulos valores como dación en pago. Sin perjuicio a lo señalado debemos tener presente que la emisión de un título valor o su entrega no produce la extinción de la relación o causa fundamental, persistiendo esta conjuntamente con la relación cartular. Por lo expuesto, lo señalado en el artículo $1233^{\circ}$ del Código Civil respecto de la extinción de la obligación primitiva tiene un fundamento distinto al erróneo criterio de la extinción de la relación causal y su reemplazo por la relación cartular. Ambas subsistirán, salvo lo señalado en el artículo en comento, respecto cuando se refiere al perjuicio del título valor, toda vez que el primer supuesto referido al pago de los títulos no requiere de mayor análisis en la medida que lógicamente extingue tanto la relación cartular como la causal.

\section{EL PRINCIPIO DE INCORPORACIÓN: CONCEPTO INELUDIBLE PARA UNA CABAL COMPRENSIÓN}

Se dice que el derecho se incorpora al título porque se encuentra íntimamente ligado a él. Procediendo a la interpretación gramatical apreciamos que la Real Academia Española indica: incorporar. 1. (Del lat. incorporare) tr. Agregar, unir una cosa a otra para que haga un todo con ella. El maestro GÓMEZ GORDOA citado por Montoya, U y Montoya, H (2012:34), señala

La incorporación del derecho en el documento hace que el documento se convierta en derecho, es tal la fuerza de la incorporación del derecho al título que hay una verdadera transfiguración del pedazo de papel para convertirse en un título de crédito, en un título valor, en un valor, sin dejar de ser un pedazo de papel.

Efectivamente cuando hablamos del Principio de Incorporación encontramos que el derecho pasa a formar parte indisoluble del documento y desde ese momento derecho y documento forman una unidad indesligable. Lo expuesto, origina que si se transfiere el título se transfiere el derecho incorporado, no siendo posible transferir independientemente derecho del título al haberse formado un cuerpo único. Los Derechos contenidos en el título valor se encuentran fusionados con él. Conforme lo señala (Solis,J:52)

En el título valor el documento y el derecho se encuentran en conexión permanente o, con imagen plástica, se puede decir que el derecho es incorporado, es compenetrado en el documento, siendo éste instrumento necesario para la circulación. La suerte del derecho está ligada a la suerte del documento.

Sánchez, F (2006:40) señala en síntesis cuales son los caracteres de este derecho: "a) El derecho que se incorpora es frecuentemente un derecho de crédito. b) el derecho incorporado tiene 
la nota de la literalidad c) El derecho incorporado es autónomo e independiente de las relaciones de carácter personal, a diferencia de una cesión ordinaria de créditos".

Pese a las afirmaciones, los ejemplos y la doctrina citada, también hallamos posiciones discordantes que cuestionan la metafórica afirmación de la incorporación a través de la fusión de derecho con documento, utilizándose términos como unión íntima o indisoluble y permanente desde el nacimiento hasta la muerte. Un crítico acérrimo de era afirmación fue Vivante, C (1939:137) "Frases superficiales que nacidas intuitivamente de la configuración material de una relación jurídica, fueron acogidas por los juristas como una regla de derecho, sin advertir su esterilidad dogmática".

Ante las diversas posiciones antagónicas sólo nos queda intentar explicar las causas de estos puntos de vista diametralmente contrarios. En primer término, debemos afirmar que la incorporación es el resultado de la evolución del ritualismo jurídico primitivo hallado en normas jurídicas arcaicas, en las cuales se utilizaban fetiches como la wadia de los longobardos, la festuca de los galos. En esos términos se expresa el maestro García - Muñoz, J (2008:56) “...De esta forma, las ideas jurídicas germanas, aun bárbaras, imaginaban que en el documento entregado a modo de wadia o festuca se contenía o incorporaba la prestación que debía realizar la persona del deudor que por medio de aquel fetiche se daba a conocer".

Luego de explicar los antecedentes de la incorporación hallamos que en la Edad Media el documento pierde la calidad de fetiche y evolucionó la creencia que el negocio se perfecciona con la entrega del documento, ello implicaba evitar el esfuerzo de distinguir el documento de lo documentado, la incorporación como tal es, por tanto un recurso metafórico.

El tema insoslayable es el referido al Principio de Incorporación con la novación como forma de extinción de las obligaciones, aspecto de análisis nos lleva a citar código civil italiano que señala en el art. 1231 "El libramiento de un documento o su renovación, la oposición o la eliminación de un término y cualquier otra modificación accesoria de la obligación no producen novación". De la misma forma el Código Civil Peruano señala en el art. 1233 "La entrega de títulos valores que constituyen órdenes o promesas de pago, sólo extinguirá la obligación primitiva cuando hubiesen sido pagados o cuando por culpa del acreedor se hubiesen perjudicado, salvo pacto en contrario". Es de verificarse en el texto de la ley que la relación causal y la obligación subyacente al título valor no muere por el hecho del nacimiento de la relación cartular, juntas existirán hasta su extinción.

El Derecho cartular, tal como se desprende de su propio significado, implica que los derechos que se incorporan encuentran un soporte material específico: el papel. De allí que nos refiramos al Derecho cartular que se desprende del significado de cartón, cartulina o específicamente papel, exceptuando en nuestro concepto a los valores representado por anotación en cuenta. Debemos hacer hincapié que conforme al Principio de Incorporación, entendemos que el derecho que es algo inmaterial, se incorpora en el título que es un objeto material y corpóreo, formándose de este modo una unidad indesligable al operar la fusión de derecho e instrumento.

\section{EL ARTÍCULO 1233 DEL CÓDIGO CIVIL Y LA MÁXIMA NEC AEQUUM EST DOLUM SUUM QUEM QUAM RELEVARE (NO ES JUSTO QUE EL PROPIO DOLO LIBERE A CUALQUIERA DE SU OBLIGACIÓN).}

Veamos diversos casos hipotéticos que pueden aclarar el panorama de lo anteriormente descrito que se plasma en la máxima $\mathrm{Nec}$ aequmm est dolum summ quem quam relevare (No es justo que el propio dolo libere a cualquiera de su obligación) ULPIANO citado por Mans, J (1979:342).

Imaginemos una relación fundamental o causal: la causa radica en un contrato de arrendamiento en el cual las partes como bien sabemos son el arrendador y el arrendatario. En nuestro caso 
hipotético, el arrendatario entrega un cheque común, girado por su persona, con cláusula no negociable a favor del arrendador. La finalidad de incorporar una cláusula no a la orden o intransferible es que la persona designada como beneficiaria del título valor sea necesariamente la persona que lo cobrará. Otra forma de lograr el mismo efecto es utilizar un cheque con cláusula para abono en cuenta. En el presente caso el arrendatario gira el cheque a la orden del arrendador con la finalidad de cancelar los meses de renta que se van generando, y por ese motivo, incorpora una cláusula no negociable pues tiene interés en que el beneficiario del título, en este caso el arrendador, sea el que lo cobre. Casos similares se presentan en las relaciones laborales cuando el empleador paga la remuneración a través de un cheque y tiene un especial interés en que sea el mismo trabajador el que lo cobre. En el presente caso el arrendatario desea acreditar el pago de la renta para no caer en causal de resolución de contrato por falta de pago al transcurrir un mes, vencerse el siguiente y transcurrir quince días adicionales si la renta se ha pactado mensualmente.

La norma jurídica tiene está compuesta por el supuesto de hecho, el nexo y la consecuencia jurídica. El supuesto de hecho recoge una situación fáctica que está más allá del derecho, nace de lo metajurídico y está vinculado a la fuente material del Derecho. El insigne maestro Alzamora, M (1987:235) señala "Las fuentes materiales consideradas en sí mismas, son hechos que tienen su propio sentido pero, además, para originar formas de derecho, deben corresponder al ámbito social humano y apuntar hacia los valores jurídicos". En el caso del artículo en comento podemos graficar la estructura de la siguiente forma (A) La entrega de títulos valores que constituyen órdenes o promesas de pago cuando por culpa del acreedor se hubiesen perjudicado (Entonces) (B) Extinguirá la obligación primitiva, salvo pacto en contrario.

En base al caso hipotético descrito en el párrafo anterior hagámonos la siguiente pregunta ¿Los cheques se protestan? La respuesta es que por lo común no se protestan, pues el protesto del cheque es facultativo y se debe efectuar dentro del plazo de presentación que es de treinta días contados desde la emisión o giro del mismo. Lo habitual en el caso del cheque es la utilización de la formalidad sustitutoria al ser un título valor por naturaleza pagadero con cargo en cuenta. La constancia de la falta de provisiones totales o parciales que deja la empresa del sistema financiero genera los mismos efectos del protesto. Qué ocurriría si el arrendador interesado en que el contrato sea resuelto por falta de pago, de manera intencional no cobra dichos títulos valores y no ejerce su derecho dentro del plazo legal. Si revisamos en artículo $1233^{\circ}$ del Código Civil no hallamos legislado el dolo sino únicamente la culpa del acreedor que genera el perjuicio de un título valor. Lo correcto en la presente situación sería interpretar que la culpa señalada en el artículo bajo comentario debe abarcar la situación antes descrita, recurriendo a la interpretación o aplicación de los principios generales del derecho, conforme al artículo VIII del Título Preliminar del Código Civil "Los jueces no pueden dejar de administrar justicia por defectos o deficiencias de la ley. En tales casos, deben aplicar los principios generales del derecho y, preferentemente, los que inspiran el derecho peruano.", adicionalmente debemos concordar el artículo precitado con el artículo IV del título preliminar que señala "La ley que establece excepciones o restringe derechos no se aplica por analogía".

Desarrollando el tema del dolo, con mayor precisión, citaremos al maestro Borda, G (1980:92) "...para que el incumplimiento se repute doloso, basta con que sea intencional: sí, además, existe propósito de perjudicar a la otra parte, resultará una doble responsabilidad: la que surge del incumplimiento doloso y la que emana del hecho ilícito".

En mérito a lo expuesto no es del todo claro si la culpa señalada en el artículo analizado es la que se refiere a la culpa inexcusable o a la culpa leve, lo que si queda claro es que la culpa excluye tanto al caso fortuito como a la fuerza mayor y al dolo. Nos indica Palacio, G (2006:476) "La culpa ocupa una posición intermedia entre dos extremos: el dolo y el caso fortuito o la fuerza mayor, porque en el dolo hay intención deliberada de no querer cumplir la obligación...”. Encontramos que la limitación 
o defecto del artículo bajo comento no se halla en la culpa, sino en no haber incorporado el dolo, tal como ejemplificamos en los párrafos anteriores.

Consideramos que existe una deficiencia en el artículo $1233^{\circ}$ al no haber incorporado el término apropiado, pues podrían darse casos excepcionales en los que el propio beneficiario no desea cobrar el título intencionalmente, obteniendo de este modo beneficios contrarios a todo criterio de justicia, lo cual no encaja en la culpa, sino en el dolo o en término cercano a él como pasaremos a desarrollar. Según nuestro parecer el supuesto de hecho limitado a la culpa es deficiente y/o insuficiente pues no cubriría situaciones como la del ejemplo expuesto, por ello consideramos que el artículo debió señalar un término adicional que permita abarcar diversas conductas que no encajan en la culpa y haga referencia al carácter intencional del incumplimiento.

Otra posición que podría surgir es cuestionar la utilización del término dolo en nuestra hipótesis, en la medida que de conformidad con el artículo $210^{\circ}$ del Código Civil se establece que el dolo causante es causa de anulación del acto jurídico. Sobre el particular, hacemos la precisión que no nos estamos refiriendo al dolo como vicio de la voluntad, sino al dolo como causa de inejecución de las obligaciones, entendido este como el incumplimiento deliberado de una obligación.

Otro aspecto importante contenido en el artículo $1233^{\circ}$ del Código Civil radica en la posibilidad de pactar que la entrega de un título valor generará plenos efectos cancelatorios indicándose de la siguiente forma "La entrega de títulos valores que constituyen órdenes o promesas de pago, sólo extinguirá la obligación primitiva cuando hubiesen sido pagados o cuando por culpa del acreedor se hubiesen perjudicado, salvo pacto en contrario". Esta posibilidad de pactar en contrario se convierte en un mecanismo que permite aparentemente solucionar la acción morosa del acreedor en el caso descrito en nuestro ejemplo sobre el arrendamiento, sin perjuicio a ello, consideramos que la norma analizada debió prever situaciones como la descrita incorporándose la conducta dolosa del beneficiario en un supuesto de hecho y correspondiente consecuencia jurídica.

El siguiente punto que debe ser desarrollado es referido a los derechos que se incorporan en los títulos valores, tal como hemos señalado anteriormente, cuando entro en vigencia el Código Civil, en el año de 1984, la ley vigente era la LTV $N^{\circ} 16587$, la cual únicamente regulaba cuatro títulos valores, razón por la que el artículo $1233^{\circ}$ refiere a órdenes o promesas de pago. El análisis que vamos a efectuar a continuación discriminará a los títulos que constituyen órdenes de pago de aquellos que constituyen promesas de pago. El cheque es un título valor que contiene e incorpora una orden de pago que a su vez se vincula con la naturaleza del mandato, a su vez la letra de cambio es un título valor que contiene una orden incondicional que el girador del instrumento dirige en contra del girado para que este cumpla con pagar una suma determinada de dinero al beneficiario de la cambial, por su parte el pagaré es un título valor que contiene una promesa de pagar una suma de dinero en un tiempo futuro, por tanto el girado es un promitente, basta poner en circulación el título valor denominado pagaré para obligarse, sin que sea necesaria su aceptación. Nos abstendremos de analizar el vale a la orden puesto que ya no se encuentra regulado en nuestra ley vigente.

Partiendo de lo señalado en el párrafo anterior, incluso tratándose de la anterior LTV $\mathrm{N}^{\circ}$ 16587 encontrábamos incorporación de derechos de distinta naturaleza. Por ejemplo, en el caso del cheque se incorpora una orden de pago que no tiene por finalidad incorporar el derecho de crédito como si ocurre por ejemplo en un pagaré o inclusive en una letra de cambio, sino que por el contrario tiene por finalidad facilitar el pago y la correspondiente extinción de la relación obligatoria. Siendo menester entender previamente el verdadero alcance de la incorporación cambiaria para comprender a cabalidad el pago con títulos valores previsto en el artículo $1233^{\circ}$ del Código Civil. 


\section{CONCLUSIONES}

El artículo $1233^{\circ}$ del Código Civil tiene una notoria influencia del Derecho extranjero y de legislaciones de larga data, como por ejemplo la legislación española, véase Código Civil Español de 1889. El Derecho Civil no puede ser ajeno a los cambios que se han venido suscitando en el Derecho Cartular. Esto se evidencia entre muchos aspectos en la amplia gama de títulos valores que se encuentran actualmente regulados en la NLTV $N^{\circ} 27287$, a diferencia de la derogada norma LTV $N^{\circ} 16587$. Se requiere de una visión crítica e innovadora que permita establecer los alcances de los diversos instrumentos cambiarios. El concepto limitado a promesas u órdenes de pago podría abarcar instrumentos cartulares de distinta naturaleza e inclusive títulos que incorporan derechos reales sobre bienes distintos al dinero y en los que opera la tradición documental. Del mismo modo, consideramos que la norma si bien es cierto no puede abarcar todos los supuestos de hecho, ello no implica que el legislador prevea supuesto normativos que cubran el mayor número de conductas o supuestos fácticos y de ese modo evitar la aplicación de principios jurídicos destinados a cubrir los "vacíos" o "deficiencias" de la ley, conforme lo señala el artículo X del Título Preliminar del Código Civil

\section{REFERENCIAS}

- Alpiniano Garcia, G. (2008). Títulos Valores - Régimen Global. Bogotá: Temis.

- Alterini, A (1997). Derecho de las Obligaciones Civiles y Comerciales. Buenos Aires: Abeledo - Perrot,

- Alzamora, M. (1987). Introducción a la ciencia del Derecho. Lima: Eddili.

- Borda, G. (1980). Teoría General de las Obligaciones. Buenos Aires: Emilio Perrot.

- De Eizaguirre, J. (2003). Derecho de los Títulos Valores. Madrid: Civitas.

- García Pita y Lastres. (1999). Introducción al Derecho de los Títulos Valores y de las Obligaciones Mercantiles. Santiago de Compostela: Tórtulo Artes Gráficas.

- Mans, J. (1979). Los Principios Generales del Derecho. Barcelona: Bosch, Casa Editorial S.A.

- Montoya, U. (1982). Comentarios a la Ley de Títulos Valores. Lima: Desarrollo S.A.

- Montoya, U y Montoya, H (2012). Comentarios a la Ley de Títulos Valores. Lima: Idemsa.

- Palacio, G. (2006). Las Obligaciones en el Derecho Civil Peruano. Lima: Huallaga.

- Sánchez, F. (2006). Instituciones de Derecho Mercantil. Navarra: Aranzadi.

- Solis, J. (1995). Temas sobre Derecho Cartular. Lima: Idemsa.

- Vivante, C. (1939). Tratado de Derecho Mercantil. Madrid: Reus.

Fecha de recepción: 30 de abril de 2018

Fecha de aceptación: 16 de junio de 2018 